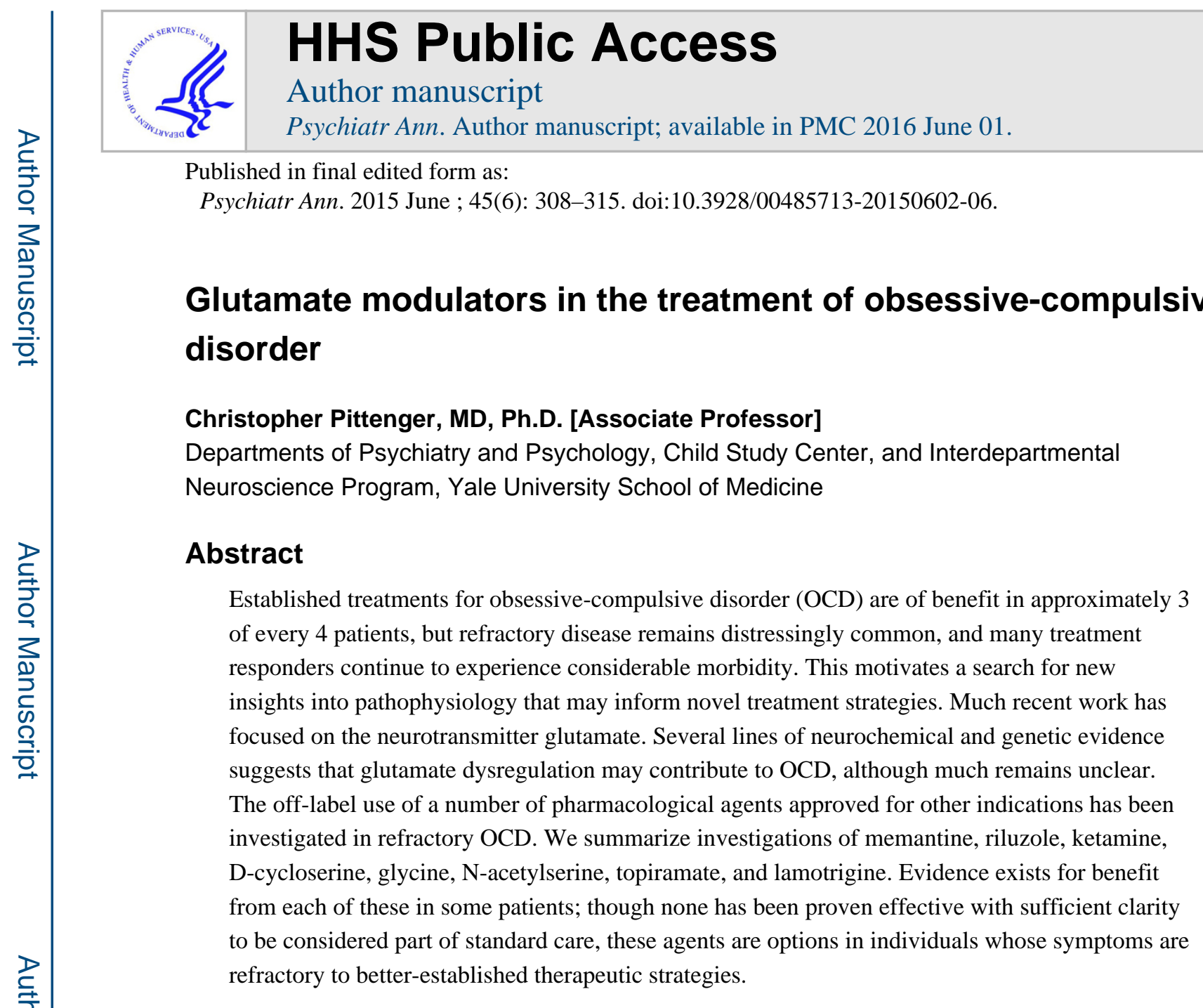

\title{
Introduction
}

Obsessive-compulsive disorder (OCD) affects approximately one person in 40 over the course of their lifetime ${ }^{1,2}$ and produces great morbidity. It is characterized, as the name suggests, by obsessions and compulsions. Obsessions are intrusive, stereotyped thoughts that often feel alien and cause significant anxiety or distress; they are typically recognized as unrealistic or excessive, and there is typically some effort to resist or neutralize them ${ }^{3}$. Common obsessions include concerns about disease or contamination, fear of harm due to one's actions or inactions, and a preoccupation with order, symmetry, or patterns ${ }^{4}$. Compulsions are repetitive or stereotyped actions undertaken to reduce anxiety or discomfort - specifically, in most cases, the discomfort association with obsessions. Typical compulsions include repetitive or stereotyped washing, checking to mitigate a fear of harm, and ordering or arranging. A diagnosis of OCD, according to the DSM, requires either obsessions or compulsions, but almost all patients have both ${ }^{3,5}$.

Effective pharmacotherapies and psychotherapies have been developed for OCD, as described elsewhere in this volume. Specifically, pharmacotherapy with the SSRI antidepressants, or the older tricyclic drug clomipramine, is effective in $50-60 \%$ of cases ${ }^{6}$. 
Evidence-based psychotherapy is efficacious in a comparable percentage, and combination treatment may be preferable in some cases ${ }^{5}$. Pharmacological augmentation with low-dose neuroleptics can be of benefit for some patients, especially those with a history of tics or Tourette syndrome ${ }^{7}$. Unfortunately, once these therapeutic options have been exhausted, the evidence to guide further treatment is thin. Approximately 30\% of cases of OCD do not response substantially to these evidence-proven treatments, and many of those who are judged to be 'responders' in studies continue to have significant symptoms and reduced quality of life ${ }^{5}$. There is thus an urgent need for new treatments for refractory disease.

Convergent recent evidence suggests that dysregulation of the neurotransmitter glutamate may contribute to OCD, and that pharmacotherapy targeting glutamate may be of benefit in refractory disease ${ }^{8}$. In this review we examine this evidence, with a particular focus on the several FDA-approved medications that have been investigated off-label in this context. The literature on the efficacy of these pharmacological approaches is mixed, and none can be claimed to be proven to work broadly. That said, there is enough promising early data on several well-tolerated medications that they represent reasonable alternatives once betterproven standard-of-care options have been exhausted ${ }^{5}$.

\section{Glutamate in the brain}

Glutamate is an amino acid that also serves as the brains' primary excitatory neurotransmitter. A review of key aspects of glutamate's function in the brain is useful to set the stage for a discussion of medications that target it ${ }^{8}$.

Excitatory glutamatergic neurons participate in virtually every circuit and system in the central nervous system ${ }^{9}$. Glutamate is released by these neurons and acts on numerous postsynaptic and presynaptic receptors in order to modulate neuronal function. These receptors can have varied effects on neuronal activity. The most straightforward is that they cause depolarization of a postsynaptic cell, which makes it more likely to fire electrically. This is the mechanism by which glutamate is an excitatory neurotransmitter: it conveys a neuronal impulse from one cell to the next by electrically exciting it. The primary receptors responsible for this action of glutamate are the AMPA and NMDA class glutamate receptors (named for drugs that were found to activate them in early in vitro pharmacological studies: alpha-methyl propionic acid and N-methyl-D-aspartate, respectively). These receptor are ligand-gated ion channels: when they bind glutamate, under appropriate circumstances, they open and allow cationic current (mostly sodium ions) to pass through the membrane, thus changing the electrical state of the cell. Both AMPA and NMDA receptors have multiple subtypes, and some medications target subsets of them, but these minutiae need not preoccupy us here.

The NMDA receptor, along with certain AMPA receptors, has additional, more long-lasting effects on postsynaptic cells because it admits calcium as well as sodium. Calcium interacts chemically with a number of postsynaptic molecules and thus triggers molecular changes above and beyond its effects on neuronal electrical activity. Depending on the specific dynamics of calcium influx, this can trigger synaptic changes, neurotrophic processes, or cell damage and even cell death. Because of this characteristic, the NMDA receptor is 
thought to be a central player in varied neuronal processes, including brain development, learning and memory, as well as psychopathology and neurodegeneration. NMDA receptors found outside the synapse have different effects than those at the synapse and may contribute importantly to cell damage when they are excessively activated ('excitoxicity').

Glutamate also acts on metabotropic glutamate receptors (mGluRs), which act exclusively through their modulation of signaling molecules within cells rather than though any direct electrical effects. For example the mGluR2 receptor is found primarily on the presynaptic axon terminal and reduces glutamate outflow. It therefore acts as a negative feedback mechanism, dampening glutamate release when ambient concentrations become excessive.

Because of its multifarious functions, it is unsurprising that the levels and dynamics of glutamate at the synapse are tightly regulated. Excess glutamate, and especially hyperstimulation of the NMDA receptor and consequent excessive calcium influx, can lead to neuronal damage and atrophy (this is termed 'excitotoxicity'); it is therefore important that synaptically released glutamate be rapidly and efficiently cleared from the extrasynaptic space. This is accomplished primarily by a set of glutamate transporters (the excitatory amino acid transporters, or EAATs). Most glutamate is cleared by the glial transporters EAAT1 and EAAT2 (also called GLT-1 and GLAST, respectively), which are found on astrocytes. A smaller percentage is cleared by the primary neuronal glutamate transporter, EAAT3. Steady-state glutamate levels outside do not approach zero, however; they are maintained in the millimolar range by other glial mechanisms, including the cystineglutamate antiporter (xCG). All of these transporters play a role in glutamatergic pharmacology, as we will see.

This brief review highlights several ways in which the glutamate 'system' differs importantly from the monoaminergic systems - dopamine, serotonin, and norepinephrine that are more frequent targets for psychopharmacology. First, whereas the monoaminergic transmitters are produced by a relatively small number of cells (those of the raphe nuclei in the case of serotonin, for example), glutamatergic cells are widely distributed and are embedded in practically every anatomical location and functional circuit in the brain. Second, and related, whereas monoaminergic transmitters are appropriately termed 'modulators', functioning primarily to gate or sculpt information flow through other circuits, glutamatergic transmission is central to the function of those circuits themselves. It is therefore misleading to speak of a glutamate 'system' at all. Glutamatergic transmission is distributed throughout the brain and is intrinsic to all of its functions; to the extent that there is a glutamate system, it constitutes the entire brain. Consequently, it is simplistic to think of any psychiatric state as being characterized simply by too little or too much glutamate.

Grossly excessive glutamate may occur in epilepsy, and globally reduced glutamate may occur in general anesthesia, but in less extreme dysregulations of neural function, abnormalities in glutamate are likely to be more subtly modulated and locally heterogeneous. Glutamate-targeting pharmacologicals therefore need to be conceptualized as modulators, not simply activators or blockers.

That said, aspects of glutamatergic neurotransmission echo themes familiar from the pharmacology of monoaminergic modulators. Like modulatory neurotransmitters, glutamate 
acts via receptors found on neuronal and glial membranes. Many psychoactive drugs are agonists (clonidine; buspirone; nicotine) or antagonists (haloperidol; propranolol) of modulatory neurotransmitter receptors; the same is true of many medications acting at glutamate receptors. Like serotonergic neurotransmission, glutamatergic transmission is terminated by reuptake transporters (EAAT1-3). These transporters are thus targets both for genetic polymorphisms and for medications that affect glutamatergic neurotransmission.

\section{Glutamate dysregulation in OCD}

Interest in the hypothesis that imbalances in glutamatergic neurotransmission contribute to OCD has grown over the past decade ${ }^{8,10-14}$. This remains a complex area of research, and while convergent evidence from multiple sources suggests that abnormalities in glutamate neurotransmission and/or homeostasis may importantly contribute to OCD, little has been established with certainty.

The most direct evidence for abnormalities in glutamate in OCD comes from examination of cerebrospinal fluid (CSF) in patients. Two such examinations, in unmedicated adult patients compared to controls, have indicated that there is elevated glutamate in the CSF of patients ${ }^{15,16}$. This suggests a fundamental dysregulation of glutamate homeostasis. Two caveats are in order, however. First, the presence of elevated glutamate in the CSF does not tell us whether the underlying abnormality is simply to much synaptic activity, overwhelming the capacity of the reuptake pumps, or a dysfunction of the reuptake system for scavenging synaptic glutamate, or a disruption of the mechanisms whereby glial cells regulate extrasynaptic glutamate independent of synaptic release, or something else entirely. It also does not tell us where in the brain the glutamate comes from - whether it is a general abnormality or a reflection of disruption in a specific brain circuit. Importantly, elevated glutamate is not seen in all subjects - indeed, in these two studies, a majority of OCD patients have glutamate levels indistinguishable from those of controls, raising the possibility that a minority of individuals with OCD have a significant disruption of glutamate regulation. Finally, elevated CSF glutamate could be a cause of OCD, or it could be an epiphenomenon of no pathophysiological significance - or even a compensation for some other underlying abnormality.

Genetics provide the most direct evidence that abnormalities in glutamate neurotransmission or homeostasis have a causal role in the pathophysiology of OCD - although here, too, the story is not yet clear. A pair of studies in 2006 associated abnormalities in the glutamate transporter EAAT3 (encoded by the gene Slclal) with OCD ${ }^{17,18}$. It is tempting to associate mutations in a glutamate transporter, which might reduce clearance, with the reported elevations of glutamate with the CSF, leading to a model of general glutamate excess in OCD. However, several observations complicate this attractive conception. First, the neuronal transporter EAAT3 is only responsible for a minority of glutamate clearance ${ }^{19}$; it is difficult to envision how an abnormality in this transporter could lead to global glutamate excess. Second, while several studies since the original reports in 2006 have supported the association of mutations in the Slclal gene with OCD, a recent meta-analysis did not support the association, calling its validity into doubt ${ }^{20}$. Finally, Slclal has not emerged as 
a candidate in more recent genome-wide investigations of the genetic architecture of OCD $^{21,22}$.

Other glutamate-related genes have been implicated in OCD. Prominent among these are a family of structural proteins that critically organize glutamatergic synapses, the SAPAP/ DLGAP proteins. Knockout of the Sapap3 gene in mice produces repetitive grooming behaviors that have been proposed to model symptoms of OCD ${ }^{23}$. DLGAP1, a related human gene, has emerged as one of the strongest candidate genes from both of the recent genome-wide investigations of OCD ${ }^{21,22}$, although in neither case did it reach the level of statistical significance necessary for its role to be considered proven. Strongly suggestive genetic associations have also been reported with the glutamate receptor genet GRIK2 and the developmental regulator PTPRD, which is involved in the development of glutamatergic synapses. These genetic findings await replication and clarification, but the frequency with which glutamate-related genes have emerged as promising candidates from such studies in recent years is becoming compelling.

A final set of findings supporting a role for glutamate dysregulation in the pathophysiology of OCD uses magnetic resonance spectroscopy, or MRS, to measure the concentration of glutamate and related molecules in the brain ${ }^{8}$. This approach has the advantage of giving measurements of glutamate-related molecules in specific brain regions, thus providing information on the spatial specificity of the hypothesized abnormalities that other approaches cannot. Indeed, early studies using this technique suggested that glutamate levels were elevated in the caudate nucleus, the input nucleus of the basal ganglia, but reduced in the anterior cingulate cortex ${ }^{24,25}$. However, these findings have not consistently replicated, and a recent review emphasized that, while some later studies have shown abnormalities in glutamate in OCD, a majority have shown no difference from control subjects ${ }^{26}$.

This brief review emphasizes both the promise and the challenges of this literature. Enough promising indications of glutamatergic abnormalities in OCD have emerged over the past decade that many investigators believe that this is likely to be a fruitful area of ongoing investigation. Nevertheless, the literature contains many suggestive findings that cannot be considered proof, and many contradictions. It is to be hoped that ongoing work over the coming years will lead to greater clarity.

\section{Glutamate-modulating medications in OCD}

Despite the questions that remain, these findings have motivated interest in the ability of glutamate-modulating medications to produce therapeutic benefit in individuals whose OCD is refractory to standard interventions. A number of such medications are already approved by the FDA for other indications, or are even available without a prescription, and they have been examined in small studies over the past ten years. The use of glutamate-modulating agents has begun to enter clinical guidelines, once better-proven standard-of-care approaches have been exhausted ${ }^{5}$.

Before summarizing this pharmacological literature it is important to note that no glutamate modulator can be said to be proven to be effective in OCD. Many early studies have been uncontrolled, and controlled studies have been small and have yielded mixed results. In most 
cases, it is therefore only appropriate to consider the use of a glutamate modulator once better-proven therapeutic approaches, such as SSRI pharmacotherapy and cognitivebehavioral therapy, have been exhausted ${ }^{6}$.

Because the nature of glutamate perturbation in OCD - if any - remains poorly understood, and because of the complex nature of glutamate neurotransmission and its regulation in the nervous system, it is not clear a priori what pharmacological modulation of glutamatergic mechanisms would be most likely to be of benefit in OCD. Research in this area has therefore been largely exploratory, with established agents with a range of effects generally FDA-approved for other indications - being tried on refractory OCD patients in small studies. Mechanistic explanations for apparent benefit has been largely post-hoc. A more rational glutamatergic pharmacotherapy must await clearer delineation of the underlying perturbations that contribute to OCD symptomatology.

\section{Treatments targeting the NMDA receptor}

Many of the glutamate modulators that have been assayed in OCD target the NMDA receptor, which can be modulated in a variety of ways.

\section{Memantine}

Memantine (brand name: Namenda) is FDA-approved for Alzheimer's disease of moderate severity ${ }^{27}$. Memantine is an antagonist of the NMDA-class glutamate receptor. In Alzheimer's disease, it is thought to be neuroprotective by reducing NMDA-mediated calcium influx and thus limiting excitoxicity ${ }^{28}$. Potent NMDA blockade has very different effects, as we will see below in the discussion of ketamine; the specific characteristics of mematine, including a low affinity for the receptor and rapid on-off kinetics, are thought to lead to its preferentially targeting extrasynaptic NMDA receptors, leaving the critical functions of synaptic receptors relatively unperturbed ${ }^{28}$.

Off-label use of memantine use in OCD has been described in a number of case series and uncontrolled studies, with generally good tolerability and many reports of benefit ${ }^{8,29}$. Individual studies have for the most part been small and not placebo-controlled, and so caution in generalizing from these reports is warranted. There have been two recent reports of placebo-controlled studies of memantine augmemtation in OCD, one in outpatients and one in inpatients, from a single center in Iran; both reported dramatic and statistically significant benefit ${ }^{30,31}$. The effects reported in these studies were more robust than those of any other controlled study of any medication in OCD - 100\% response in one case - which raises questions about whether the investigators were diagnosing and assessing OCD in the same way as others. These questions aside, memantine is FDA-approved and has a relatively benign side effect profile and thus may be reasonable to consider in refractory cases, once better-proven agents have been exhausted.

\section{Ketamine}

Ketamine is a much more potent noncompetitive antagonist of the NMDA receptor than memantine, and its effects are quite different. Ketamine is used clinically as an anesthetic; it also has abuse potential. Neuropsychiatric interest in ketamine derives from its effects at 
subanesthetic doses, which are psychotomimetic and dissociative and, remarkably, produce an almost immediate antidepressant effects that last for up to 2 weeks after a single infusion ${ }^{32}$. This striking observation has spurred interest in whether ketamine infusion might be of similar benefit in OCD. Results have been mixed. An open-label trial in 10 treatment-refractory patients showed benefit to comorbid depression but a clinically insignificant effect on OCD symptoms ${ }^{33}$. However, a subsequent placebo-controlled crossover trial in unmedicated, non-depressed patients suggested significant benefit ${ }^{34}$. Both of these studies were small. It remains to be determined whether a single ketamine infusion will prove to be of benefit in a subset of patients.

Excitement over ketamine's antidepressant effects, both at the level of clinical studies ${ }^{32}$ and at the level of mechanistic investigations ${ }^{35}$, is driving significant investment by pharmaceutical companies, and new NMDA-modulating agents are likely to become available in the near future; off-label use of these new agents in OCD will be of great interest.

\section{Glycine}

The amino acid glycine is an obligatory co-transmitter at the NMDA glutamate receptor: glycine cannot open the receptor by itself, but it is necessary for glutamate's effects. Modulating brain glycine is therefore an indirect way to affect the activity of the receptor. A small controlled study of glycine itself suggested benefit; unfortunately, large amounts of glycine are required, and it produces significant nausea that led to frequent dropouts ${ }^{36}$. Glycine is unlikely to be a widely useful treatment, even if it proves efficacious, due to these side effects. Glycine levels can be indirectly modulated, however, by an inhibitor of the primary glycine transporter, GLY-T1. The naturally occurring compound sarcosine inhibits GLY-T1, and an uncontrolled study suggests that it may be of benefit in refractory OCD ${ }^{37}$. A placebo-controlled study of the more specific GLY-T1 inhibitor bitopertin has recently been completed by Hoffmann-La Roche (clinicaltrials.gov: NCT01674361); results are pending.

\section{D-cycloserine}

D-cycloserine is a modified amino acid that acts as an agonist at the glycine site on the NMDA receptor. It has been used in a rather different way than glycine itself. Because the NMDA receptor is critical for the mechanisms of synaptic plasticity that underlie learning, potentiating its function can enhance learning. This has been clearly shown in animal studies, in which D-cycloserine can potentiate extinction learning ${ }^{38}$. Since cognitivebehavioral therapy (CBT) is a form of structured learning, potentiating its mechanisms may enhance its speed or efficacy ${ }^{39,40}$. An initial study in patients with acrophobia validated this approach: D-cycloserine given prior to computerized exposure therapy significantly improved clinical response ${ }^{41}$.

Several studies have applied this approach to the treatment of OCD, with mixed results ${ }^{42}$. Variables that explain the heterogeneity of response may include the D-cycloserine dose, the timing (i.e. how long before psychotherapy sessions it is given), the nature of the CBT, and the nature of the target patient population. The effects of D-cycloserine appear to decrease 
over time, such that the benefit, when it is seen, is an acceleration of CBT, rather than a change in asymptotic efficacy ${ }^{42}$. The benefit of D-cycloserine augmentation of CBT is sufficiently unclear that it has not entered widespread use. The concept of using a pharmacological strategy to increase the efficacy of CBT, however, is an exciting one, and further advances in this area may make a qualitative difference in the efficacy of care in the future.

\section{The heterogeneity of NMDA-targeting strategies in the treatment of OCD}

The broad range of strategies that have been investigated in OCD, each of which has some data supporting its efficacy, merits comment. The treatment strategies summarized above modulate the NMDA receptor in four distinct ways. Memantine treatment represents chronic antagonism of the NMDA receptor. Ketamine infusion, in contrast, achieves more potent, acute antagonism. Glycine (and GLY-T antagonism) chronically potentiates NMDA function, while D-cycloserine transiently potentiates it prior to CBT.

It seems unlikely, though not impossible, that such disparate strategies could all be of benefit in the same patients. Another possibility is that varied pathophysiologies lead to clinically similar presentations of OCD, and different pharmacological mechanisms are efficacious in each. Alternatively, some of these approaches may prove in the end not to be effective after all - all of the studies summarized above are small, and most are uncontrolled, making false positive results a real danger. Only further research will resolve these questions and establish the role, if any, of NMDA modulation in the pharmacological treatment of OCD.

\section{Other glutamate modulators}

\section{Riluzole}

The first glutamate modulator to be tested in refractory OCD was not an NMDA modulator, but rather the drug riluzole (brand name: Rilutek), a unique medication that is approved for the treatment of amyotrophic lateral sclerosis ${ }^{43}$. Riluzole has several mechanisms of action; it appears to have a net glutamate-lowering effect, by reducing glutamate release from axon terminals and by potentiating glutamate uptake by the transporters on glial cells (EAAT2 and EAAT3) ${ }^{43}$. An initial case report and two follow-up open-label studies suggested benefit in a substantial fraction of patients whose OCD is refractory to standard pharmacotherapy ${ }^{44-46}$. Unfortunately, a more recent controlled study did not show a statistically significant benefit ${ }^{47}$. This controlled study did show a trend suggesting modest benefit; but it suggests that any such benefit is sufficiently modest that it would require much larger studies to definitively prove. A similar study in children produced more definitively negative results: a placebo-controlled investigation of riluzole in 60 patients showed no evidence of benefit whatsoever ${ }^{48}$. While riluzole may yet prove to be of benefit in some adults, therefore, the evidence does not at present support its widespread use, until better-proven options have been exhausted. 


\section{$\mathrm{N}$-acetylcysteine}

$\mathrm{N}$-acetylcysteine, or NAC, is a modified form of the amino acid cysteine and an antioxidant. It can also modulate extrasynaptic glutamate levels through its interaction with the glial cystine-glutamate antiporter ${ }^{8}$. This, together with the fact that it is cheap, is available without a prescription, and has a benign side-effect profile, has motivated trials of this agent in OCD, as well as in several other neuropsychiatric conditions. An early case report suggested benefit from the addition of NAC to ongoing SSRI treatment ${ }^{49}$. More recently, a controlled study, from a different research group in Iran, has suggested benefit ${ }^{50}$. Studies in trichotillomania, which is classified together with OCD in the DSM- $5^{3}$, have been mixed, with one high-quality study suggesting substantial benefit in adults 51 , while a subsequent study in adolescents showed no benefit ${ }^{52}$. More research is needed to clarify the benefits of NAC. That said, its low cost and benign side-effect profile make it a potentially attractive agent to try, especially in pediatric patients and others in whom side effects may be of particular concern.

\section{Topiramate}

The anti-epileptic drug topiramate interacts with voltage-gated calcium channels and thereby modulates glutamate levels (in addition to other effects). Controlled trials have suggested modest benefit from topiramate; the effect may be greater on obsessions than on compulsions ${ }^{53,54}$. Side effects, especially cognitive slowing, can be limiting with this agent.

\section{Lamotrigine}

Lamotrigine is an antiepileptic and mood stabilizer; like riluzole, it reduces glutamate outflow through inhibition of certain presynaptic voltage-gated sodium channels. (It is not thought to potentiate glutamate reuptake, as riluzole does.) Early work showed no improvement from lamotrigine treatment in $\mathrm{OCD}^{55}$, but a recent controlled trial suggested clear benefit ${ }^{56}$. More work is needed.

\section{Conclusion}

The evidence for glutamate dysregulation in OCD is provocative but remains inconclusive. Nevertheless, this hypothesis has motivated a number of studies of available glutamate modulators in refractory disease. Initial data, while not sufficient for glutamate modulation to be considered a proven treatment, makes these glutamate modulators reasonable options to consider in OCD that proves refractory to better-proven standard-of-care treatment strategies ${ }^{5}$.

We have summarized the primary agents that have been investigated in this context. The evidence in favor of these agents is mixed, and none of it is definitive. It is to be hoped that further investigations will establish which of these pharmacological strategies is truly of benefit, and in which patients. In the mean time, treatment of refractory disease remains an often-frustrating matter of trial and error. Despite this, recent evidence supporting glutamate modulators increases the number of arrows in the psychopharmacologist's armamentarium and may provide hope for that fraction of patients - unfortunately large - who remain profoundly symptomatic despite the best proven treatments we now have to offer. 


\section{References}

1. Kessler RC, Petukhova M, Sampson NA, Zaslavsky AM, Wittchen HU. Twelve-month and lifetime prevalence and lifetime morbid risk of anxiety and mood disorders in the United States. International journal of methods in psychiatric research. Sep; 2012 21(3):169-184. [PubMed: 22865617]

2. Ruscio AM, Stein DJ, Chiu WT, Kessler RC. The epidemiology of obsessive-compulsive disorder in the National Comorbidity Survey Replication. Molecular psychiatry. Jan; 2010 15(1):53-63. [PubMed: 18725912]

3. American Psychiatric Association., American Psychiatric Association. DSM-5 Task Force. Diagnostic and statistical manual of mental disorders : DSM-5. 5th. American Psychiatric Association; Washington, D.C.: 2013.

4. Bloch MH, Landeros-Weisenberger A, Rosario MC, Pittenger C, Leckman JF. Meta-analysis of the symptom structure of obsessive-compulsive disorder. Am J Psychiatry. Dec; 2008 165(12):15321542. [PubMed: 18923068]

5. Koran LM, Hanna GL, Hollander E, Nestadt G, Simpson HB, American Psychiatric A. Practice guideline for the treatment of patients with obsessive-compulsive disorder. The American journal of psychiatry. Jul; 2007 164(7 Suppl):5-53. [PubMed: 17849776]

6. Pittenger C, Bloch MH. Pharmacological treatment of obsessive-compulsive disorder. The Psychiatric clinics of North America. Sep; 2014 37(3):375-391. [PubMed: 25150568]

7. Bloch MH, Landeros-Weisenberger A, Kelmendi B, Coric V, Bracken MB, Leckman JF. A systematic review: antipsychotic augmentation with treatment refractory obsessive-compulsive disorder. Molecular psychiatry. Jul; 2006 11(7):622-632. [PubMed: 16585942]

8. Pittenger C, Bloch MH, Williams K. Glutamate abnormalities in obsessive compulsive disorder: neurobiology, pathophysiology, and treatment. Pharmacology \& therapeutics. Dec; 2011 132(3): 314-332. [PubMed: 21963369]

9. Shepherd, GM. The synaptic organization of the brain. 5th. Oxford University Press; Oxford ; New York: 2004.

10. Pittenger C, Krystal JH, Coric V. Glutamate-modulating drugs as novel pharmacotherapeutic agents in the treatment of obsessive-compulsive disorder. NeuroRx : the journal of the American Society for Experimental NeuroTherapeutics. Jan; 2006 3(1):69-81. [PubMed: 16490414]

11. Ting JT, Feng G. Glutamatergic Synaptic Dysfunction and Obsessive-Compulsive Disorder. Current chemical genomics. Jan 1.2008 2:62-75. [PubMed: 19768139]

12. Wu K, Hanna GL, Rosenberg DR, Arnold PD. The role of glutamate signaling in the pathogenesis and treatment of obsessive-compulsive disorder. Pharmacology, biochemistry, and behavior. Feb; 2012 100(4):726-735.

13. Pauls DL, Abramovitch A, Rauch SL, Geller DA. Obsessive-compulsive disorder: an integrative genetic and neurobiological perspective. Nature reviews. Neuroscience. Jun; 2014 15(6):410-424. [PubMed: 24840803]

14. Kariuki-Nyuthe C, Gomez-Mancilla B, Stein DJ. Obsessive compulsive disorder and the glutamatergic system. Current opinion in psychiatry. Jan; 2014 27(1):32-37. [PubMed: 24270485]

15. Bhattacharyya S, Khanna S, Chakrabarty K, Mahadevan A, Christopher R, Shankar SK. Anti-brain autoantibodies and altered excitatory neurotransmitters in obsessive-compulsive disorder. Neuropsychopharmacology : official publication of the American College of Neuropsychopharmacology. Nov; 2009 34(12):2489-2496. [PubMed: 19675532]

16. Chakrabarty K, Bhattacharyya S, Christopher R, Khanna S. Glutamatergic dysfunction in OCD. Neuropsychopharmacology : official publication of the American College of Neuropsychopharmacology. Sep; 2005 30(9):1735-1740. [PubMed: 15841109]

17. Arnold PD, Sicard T, Burroughs E, Richter MA, Kennedy JL. Glutamate transporter gene SLC1A1 associated with obsessive-compulsive disorder. Archives of general psychiatry. Jul; 2006 63(7): 769-776. [PubMed: 16818866]

18. Dickel DE, Veenstra-VanderWeele J, Cox NJ, et al. Association testing of the positional and functional candidate gene SLC1A1/EAAC1 in early-onset obsessive-compulsive disorder. Archives of general psychiatry. Jul; 2006 63(7):778-785. [PubMed: 16818867] 
19. Danbolt NC. Glutamate uptake. Progress in neurobiology. Sep; 2001 65(1):1-105. [PubMed: 11369436]

20. Stewart SE, Mayerfeld C, Arnold PD, et al. Meta-analysis of association between obsessivecompulsive disorder and the 3' region of neuronal glutamate transporter gene SLC1A1. American journal of medical genetics. Part B, Neuropsychiatric genetics : the official publication of the International Society of Psychiatric Genetics. Jun; 2013 162B(4):367-379.

21. Mattheisen M, Samuels JF, Wang Y, et al. Genome-wide association study in obsessivecompulsive disorder: results from the OCGAS. Molecular psychiatry. May 13.2014

22. Stewart SE, Yu D, Scharf JM, et al. Genome-wide association study of obsessive-compulsive disorder. Molecular psychiatry. Jul; 2013 18(7):788-798. [PubMed: 22889921]

23. Welch JM, Lu J, Rodriguiz RM, et al. Cortico-striatal synaptic defects and OCD-like behaviours in Sapap3-mutant mice. Nature. Aug 23; 2007 448(7156):894-900. [PubMed: 17713528]

24. Rosenberg DR, MacMaster FP, Keshavan MS, Fitzgerald KD, Stewart CM, Moore GJ. Decrease in caudate glutamatergic concentrations in pediatric obsessive-compulsive disorder patients taking paroxetine. Journal of the American Academy of Child and Adolescent Psychiatry. Sep; 2000 39(9):1096-1103. [PubMed: 10986805]

25. Rosenberg DR, Mirza Y, Russell A, et al. Reduced anterior cingulate glutamatergic concentrations in childhood OCD and major depression versus healthy controls. Journal of the American Academy of Child and Adolescent Psychiatry. Sep; 2004 43(9):1146-1153. [PubMed: 15322418]

26. Brennan BP, Rauch SL, Jensen JE, Pope HG Jr. A critical review of magnetic resonance spectroscopy studies of obsessive-compulsive disorder. Biological psychiatry. Jan 1; 2013 73(1): 24-31. [PubMed: 22831979]

27. Yang Z, Zhou X, Zhang Q. Effectiveness and safety of memantine treatment for Alzheimer's disease. Journal of Alzheimer's disease : JAD. 2013; 36(3):445-458. [PubMed: 23635410]

28. Parsons CG, Stoffler A, Danysz W. Memantine: a NMDA receptor antagonist that improves memory by restoration of homeostasis in the glutamatergic system--too little activation is bad, too much is even worse. Neuropharmacology. Nov; 2007 53(6):699-723. [PubMed: 17904591]

29. Sani G, Serra G, Kotzalidis GD, et al. The role of memantine in the treatment of psychiatric disorders other than the dementias: a review of current preclinical and clinical evidence. CNS drugs. Aug 1; 2012 26(8):663-690. [PubMed: 22784018]

30. Ghaleiha A, Entezari N, Modabbernia A, et al. Memantine add-on in moderate to severe obsessivecompulsive disorder: randomized double-blind placebo-controlled study. Journal of psychiatric research. Feb; 2013 47(2):175-180. [PubMed: 23063327]

31. Haghighi M, Jahangard L, Mohammad-Beigi H, et al. In a double-blind, randomized and placebocontrolled trial, adjuvant memantine improved symptoms in inpatients suffering from refractory obsessive-compulsive disorders (OCD). Psychopharmacology. Aug; 2013 228(4):633-640. [PubMed: 23525525]

32. Krystal JH, Sanacora G, Duman RS. Rapid-acting glutamatergic antidepressants: the path to ketamine and beyond. Biological psychiatry. Jun 15; 2013 73(12):1133-1141. [PubMed: 23726151]

33. Bloch MH, Wasylink S, Landeros-Weisenberger A, et al. Effects of ketamine in treatmentrefractory obsessive-compulsive disorder. Biological psychiatry. Dec 1; 2012 72(11):964-970. [PubMed: 22784486]

34. Rodriguez CI, Kegeles LS, Levinson A, et al. Randomized controlled crossover trial of ketamine in obsessive-compulsive disorder: proof-of-concept. Neuropsychopharmacology : official publication of the American College of Neuropsychopharmacology. Nov; 2013 38(12):2475-2483. [PubMed: 23783065]

35. Duman RS, Aghajanian GK. Synaptic dysfunction in depression: potential therapeutic targets. Science. Oct 5; 2012 338(6103):68-72. [PubMed: 23042884]

36. Greenberg WM, Benedict MM, Doerfer J, et al. Adjunctive glycine in the treatment of obsessivecompulsive disorder in adults. Journal of psychiatric research. Mar; 2009 43(6):664-670.

[PubMed: 19046587]

Psychiatr Ann. Author manuscript; available in PMC 2016 June 01. 
37. Wu PL, Tang HS, Lane HY, Tsai CA, Tsai GE. Sarcosine therapy for obsessive compulsive disorder: a prospective, open-label study. Journal of clinical psychopharmacology. Jun; 2011 31(3):369-374. [PubMed: 21508860]

38. Walker DL, Ressler KJ, Lu KT, Davis M. Facilitation of conditioned fear extinction by systemic administration or intra-amygdala infusions of D-cycloserine as assessed with fear-potentiated startle in rats. The Journal of neuroscience : the official journal of the Society for Neuroscience. Mar 15; 2002 22(6):2343-2351. [PubMed: 11896173]

39. Krystal JH, Tolin DF, Sanacora G, et al. Jul; 2009 14(13-14):690-697.

40. Myers KM, Carlezon WA Jr. Davis M. Glutamate receptors in extinction and extinction-based therapies for psychiatric illness. Neuropsychopharmacology : official publication of the American College of Neuropsychopharmacology. Jan; 2011 36(1):274-293. [PubMed: 20631689]

41. Ressler KJ, Rothbaum BO, Tannenbaum L, et al. Cognitive enhancers as adjuncts to psychotherapy: use of D-cycloserine in phobic individuals to facilitate extinction of fear. Archives of general psychiatry. Nov; 2004 61(11):1136-1144. [PubMed: 15520361]

42. Norberg MM, Krystal JH, Tolin DF. A meta-analysis of D-cycloserine and the facilitation of fear extinction and exposure therapy. Biological psychiatry. Jun 15; 2008 63(12):1118-1126. [PubMed: 18313643]

43. Pittenger C, Coric V, Banasr M, Bloch M, Krystal JH, Sanacora G. Riluzole in the treatment of mood and anxiety disorders. CNS drugs. 2008; 22(9):761-786. [PubMed: 18698875]

44. Coric V, Milanovic S, Wasylink S, Patel P, Malison R, Krystal JH. Beneficial effects of the antiglutamatergic agent riluzole in a patient diagnosed with obsessive-compulsive disorder and major depressive disorder. Psychopharmacology. May; 2003 167(2):219-220. [PubMed: 12658528]

45. Coric V, Taskiran S, Pittenger C, et al. Riluzole augmentation in treatment-resistant obsessivecompulsive disorder: an open-label trial. Biological psychiatry. Sep 1; 2005 58(5):424-428. [PubMed: 15993857]

46. Pittenger C, Kelmendi B, Wasylink S, Bloch MH, Coric V. Riluzole augmentation in treatmentrefractory obsessive-compulsive disorder: a series of 13 cases, with long-term follow-up. Journal of clinical psychopharmacology. Jun; 2008 28(3):363-367. [PubMed: 18480706]

47. Pittenger C, Bloch MH, Wasylink S, et al. Riluzole augmentation in treatment-refractory obsessive-compulsive disorder: a pilot placebo-controlled trial. J. Clin. Psychiatry. in press;in press.

48. Grant PJ, Joseph LA, Farmer CA, et al. 12-week, placebo-controlled trial of add-on riluzole in the treatment of childhood-onset obsessive-compulsive disorder. Neuropsychopharmacology : official publication of the American College of Neuropsychopharmacology. May; 2014 39(6):1453-1459. [PubMed: 24356715]

49. Lafleur DL, Pittenger C, Kelmendi B, et al. N-acetylcysteine augmentation in serotonin reuptake inhibitor refractory obsessive-compulsive disorder. Psychopharmacology. Jan; 2006 184(2):254256. [PubMed: 16374600]

50. Afshar H, Roohafza H, Mohammad-Beigi H, et al. N-acetylcysteine add-on treatment in refractory obsessive-compulsive disorder: a randomized, double-blind, placebo-controlled trial. Journal of clinical psychopharmacology. Dec; 2012 32(6):797-803. [PubMed: 23131885]

51. Grant JE, Odlaug BL, Kim SW. A double-blind, placebo-controlled study of N-acetyl cysteine plus naltrexone for methamphetamine dependence. European neuropsychopharmacology : the journal of the European College of Neuropsychopharmacology. Nov; 2010 20(11):823-828. [PubMed: 20655182]

52. Bloch MH, Panza KE, Grant JE, Pittenger C, Leckman JF. N-Acetylcysteine in the treatment of pediatric trichotillomania: a randomized, double-blind, placebo-controlled add-on trial. Journal of the American Academy of Child and Adolescent Psychiatry. Mar; 2013 52(3):231-240. [PubMed: 23452680]

53. Berlin HA, Koran LM, Jenike MA, et al. Double-blind, placebo-controlled trial of topiramate augmentation in treatment-resistant obsessive-compulsive disorder. The Journal of clinical psychiatry. May; 2011 72(5):716-721. [PubMed: 20816027] 
54. Mowla A, Khajeian AM, Sahraian A, Chohedri AH, Kashkoli F. Topiramate Augmentation in Resistant OCD: A Double-Blind Placebo-Controlled Clinical Trial. CNS spectrums. Nov 1.2010

55. Kumar TC, Khanna S. Lamotrigine augmentation of serotonin re-uptake inhibitors in obsessivecompulsive disorder. The Australian and New Zealand journal of psychiatry. Jun; 2000 34(3):527528. [PubMed: 10881981]

56. Bruno A, Mico U, Pandolfo G, et al. Lamotrigine augmentation of serotonin reuptake inhibitors in treatment-resistant obsessive-compulsive disorder: a double-blind, placebo-controlled study.

Journal of psychopharmacology. Nov; 2012 26(11):1456-1462. [PubMed: 22351381] 